\title{
O Emprego da Engenharia Tecidual na Odontologia
}

The Use of Tissue Engineering in Dentistry

\section{Luciano Casagrande ${ }^{1}$, Isabel da SilvaLauxen ${ }^{2}$, Marilene Issa Fernandes ${ }^{3}$}

\begin{abstract}
Advances in molecular and cellular biology have contributed to the development of techniques to repair, or even regenerate, organs and tissues that have been injured by diseases, traumas and congenital deformities. Tissue engineering is an interdisciplinary field that applies the principles of engineering, biology and the clinical sciences to the development of biological substitutes that are able to maintain, restore or improve the function of organs and tissues. This new science is based on three components: cells, biocompatible matrices and bioactive molecules which are responsible for morphogenic signals. The cells most often used are stem cells. This article is aimed to bring dental surgeons up to date on tissue engineering concepts and the context in which tissue engineering is being studied within Dentistry; specifically, areas related to periodontium and pulp.
\end{abstract}

Keywords: tissue engineering; dental pulp; periodontium

\section{Resumo}

Avanços na biologia molecular e celular vêm contribuindo para o desenvolvimento de técnicas na área de reparo e regeneração de órgãos e tecidos lesados por doenças, traumas e deformidades congênitas. A engenharia tecidual é um campo multidisciplinar que se vale de princípios da engenharia, biologia e ciências clínicas para o desenvolvimento de substitutos biológicos capazes de manter, restaurar ou aprimorar a função de órgãos e tecidos. Esta nova ciência baseia-se em três componentes: células, matrizes biocompátiveis e moléculas bioativas, que são responsáveis pela sinalização morfogenética. As células freqüentemente utilizadas são as células-tronco. O objetivo deste artigo é atualizar os cirurgiões dentistas nos conceitos de engenharia tecidual e no contexto em que esta ciência vem sendo estudada na Odontologia, especialmente nas áreas relacionadas ao periodonto e tecido pulpar.

Palavras-chave: engenharia tecidual, polpa dentária, periodonto.
${ }^{1}$ Mestre e Doutor em Odontologia - Odontopediatria, Professor Adjunto de Clínica Odontológica - Faculdade de Odontologia da UNIFRA

${ }^{2}$ Bióloga, Laboratório de Citologia e Patologia Bucal - Faculdade de Odontologia da UFRGS

${ }^{3}$ Mestre e Doutor em Odontologia - Patologia Bucal, Professor Adjunto Periodontia Faculdade de Odontologia da UFRGS

Correspondência: Isabel da Silva Lauxen Faculdade de Odontologia da UFRGS Endereço: R. Ramiro Barcelos, 2492 Sala 503 - CEP 90035085011

Porto Alegre - RS, Brasil

Fone:+ 5551 3308-5011

E-mail: isabel.lauxen@ufrgs.br

Data de Submissão: 03/10/2008

Data de Aceite: 04/11/2009

\section{Introdução}

Avanços na área de biologia molecular e celular têm contribuído para o desenvolvimento de técnicas de reparo ou, até mesmo, de regeneração de órgãos e tecidos injuriados por doenças, traumas e deformidades congênitas. Langer e Vacanti (1993) foram os pioneiros na descrição do conceito de engenharia tecidual como sendo um campo interdisciplinar que aplica princípios da engenharia, biologia e ciências clínicas para o desenvolvimento de substitutos biológicos que possam manter, restaurar, ou melhorar a função de órgãos e tecidos. Essa nova ciência está embasada na utilização de células-tronco, de matrizes biocompatíveis e de moléculas bioativas responsáveis pelos sinais morfogênicos.

\section{O que são Células-tronco}

A célula-tronco pode se dividir em células idênticas a ela ou em diferentes tipos de células, sendo distintas no tocante à origem e ao potencial de diferenciação. Basicamente, existem dois tipos de células-tronco: as células-tronco embrionárias e as somáticas ou adultas. As células-tronco embrionárias são derivadas da massa celular interna do blastocisto, uma condensação de células primordiais (4-5 dias de idade). Estas células são classificadas como totipotentes, têm a capacidade de formar qualquer tipo de tecido que compõe o organismo adulto e potencial de proliferação ilimitado. Uma célula só é considerada célula-tronco quando mantida no seu nicho (matriz, outras células, fatores solúveis). Essas células podem ser expostas in vitro a combinações específicas de fatores de diferenciação e de crescimento, os quais podem induzir sua diferenciação nas direções desejadas (GILBERT, 2000; LEITE SEGUNDO e VASCONCELOS, 2007). As células-tronco adultas são classificadas como pluripotentes, são células indiferenciadas que permanecem quiescentes nos tecidos e que quando estimuladas podem gerar tipos celulares compatíveis com o tecido no qual elas residem. Possuem a capacidade de auto-renovação e sua função principal é manter e reparar os tecidos nos quais se encontram. Além disto, podem também formar tipos celulares especializados de outros tecidos no caso de serem transplantadas, se reprogramando de 
acordo com o novo ambiente, o que é conhecido como transdiferenciação ou plasticidade (BJORSON et al., 1999; ANDERSON, GAGE, WEISSMAN, 2001). Entretanto, relatos sugerem que os transplantes de células-tronco adultas para tecidos diferentes de seus nichos resultam na formação de um ou poucos tipos celulares (LEITE SEGUNDO e VASCONCELOS, 2007). A população de célulastronco adultas varia de acordo com o tecido e sua capacidade regenerativa. As células-tronco adultas hematopoiéticas (medula óssea, cordão umbilical, sangue periférico) são as mais conhecidas. Já foram encontradas células-tronco também no cérebro, vasos sanguíneos, músculo esquelético, osso, tecido epitelial, fígado, tecido adiposo, ligamento periodontal e na polpa dental (HARADA et al., 1999; FUCHS e SEGRE, 2000; GRONTHOS et al., 2000; BLAU et al., 2001; GRONTHOS et al., 2002; SHI e GRONTHOS, 2003; MIURA et al., 2003).

As células-tronco adultas, por definição, são capazes de se diferenciarem em, pelo menos, duas linhagens. As condições específicas que permitem que as células-tronco permaneçam quiescentes dentro de órgãos por alguns anos até serem ativadas por doenças ou danos teciduais ainda são desconhecidas (THESLEFF e TUMMERS, 2003).

Avanços científicos têm criado expectativas de que tecidos adultos possam ser replicados por métodos biológicos, sendo utilizados na regeneração de tecidos destruídos ou correção de anormalidades congênitas. A engenharia tecidual é o campo da ciência que estuda a restauração funcional e fisiológica de estruturas teciduais deterioradas ou perdidas, e se baseia no manejo de célulastronco, desenvolvimento de scaffolds (matrizes que criam uma base para orientar a arquitetura tecidual) e substâncias indutoras do crescimento e diferenciação tecidual (HOHLFELD et al., 2005 e LEITE SEGUNDO e VASCONCELOS, 2007).

\section{Estudos com Engenharia Tecidual em Odontologia}

De acordo com o exposto a engenharia tecidual pode ser empregada em diferentes áreas da Odontologia. Optamos por explorar seu emprego na polpa e periodonto, por serem as áreas de atuação deste grupo.

Polpa

Nos últimos anos, o potencial da engenharia tecidual no reparo e regeneração de estruturas dentais tomou grandes proporções. A identificação e caracterização de células-tronco no órgão pulpar de dentes permanentes (GRONTHOS et al., 2000) e até mesmo em dentes decíduos (MIURA et al., 2003), associada à possibilidade da sua utilização com fins terapêuticos, estimula as especulações para o desenvolvimento de uma "terceira dentição", o que possibilitaria o restabelecimento da função mastigatória e estética com terapias biológicas.

Para que a engenharia tecidual se constitua em uma opção terapêutica viável na regeneração do complexo dentino-pulpar, são necessárias estruturas tridimensionais de suporte celular e que permitam a re-vascularização do tecido pulpar (NAKASHIMA e AKAMINE, 2005).

Os scaffolds são estruturas tridimensionais que proporcionam um microambiente capaz de permitir a adesão e migração celular. Esses devem apresentar características físicas, químicas e biológicas favoráveis ao crescimento e diferenciação celular, além de microporosidade para permitir a conectividade entre as células semeadas no scaffold implantado e o tecido adjacente, facilitando o transporte de nutrientes e a eliminação dos produtos do metabolismo celular (SACHLOS e CZERNUSKA, 2003; NAKASHIMA e AKAMINE, 2005).

Dependendo da finalidade de aplicação, os scaffolds podem ser biológicos ou sintéticos, biodegradáveis ou permanentes. Scaffolds contendo componentes inorgânicos tais como, hidroxiapatita e fosfato de cálcio, são usualmente empregados na neoformação óssea guiada (JADLOWIEC, CELIL e HOLLINGER, 2003). Polímeros naturais, a base de colágeno e glicosaminoglicano, oferecem boa interação com os tecidos.

Polímeros sintéticos permitem a manipulação das propriedades físico-químicas como o índice de degradação, tamanho das microporosidades e resistência mecânica. Usualmente, os polímeros sintéticos utilizados na engenharia tecidual são à base de ácido poli-L-lático (poly-L-lactic acid - PLLA), ácido poli-glicólico (poly glycolic acid - PGA), e seus co-polímeros como o ácido poli-lático coglicólico (poly lactic-co-glycolic acid - PLGA). Essas matrizes poliméricas têm demonstrado bons resultados nas aplicações de engenharia tecidual em função da capacidade de sustentar 0 crescimento e a diferenciação celular (TAYLOR et al., 1994). Além disso, a taxa de degradação observada é compatível com o índice de formação tecidual, isto significa que as células fabricam sua própria matriz tecidual enquanto o scaffold fornece integridade estrutural, até que o tecido neoformado se apresente em condições para autosustentação (FREED et al., 1994). Matrizes a base de polímeros biodegradáveis (PGA/PLLA) serviram para a engenharia de estruturas dentais com características muito similares à coroa de dentes naturais (YOUNG et al., 2002).

Os fatores de crescimento, moléculas bioativas ou fatores morfogenéticos são proteínas que se ligam a receptores celulares específicos induzindo a proliferação/diferenciação celular (WINGARD e DEMETRI, 1999). Atualmente, uma variedade de moléculas bioativas, com funções específicas têm sido empregadas na terapia com células-tronco e na engenharia tecidual (RAMOSHEBI et al., 2002; VASITA e KATTI, 2006). Diversos fatores de crescimento podem ser utilizados para controlar a atividade de células-tronco, seja aumentando o índice de proliferação, induzindo a diferenciação em outro tipo celular, ou ainda, estimulando as células à síntese e secreção de matriz mineralizada (MARTIN et al., 1998; STEVENS et al., 2005).

O tecido da polpa dental é reconhecido por sua alta capacidade de reparo. A formação da barreira mineralizada em locais de exposição pulpar após o capeamento direto é um exemplo clássico do potencial de reparo da polpa dentária (SMITH, 2000). A preservação da vitalidade do complexo dentino-pulpar após injúria depende de aspectos como extensão do dano, vascularização, idade do paciente, idade do dente, número de foramens, processos de atividade e sinalização celular. Vários fatores exercem papel fundamental nos eventos formadores e reparadores do complexo dentino-pulpar. As proteínas formadoras da matriz extra-celular, tais como colágeno I, colágeno III, fibronectina, tenascina e fatores de crescimento exercem papel de destaque (NAKASHIMA e REDDI, 2003; GOLDBERG et al., 2003; TZIAFAS, 2004).

A descoberta de que células-tronco de alta qualidade podem ser extraídas da polpa dental, inclusive de dentes decíduos esfoliados, aumentaram as possibilidades para a regeneração do complexo dentino-pulpar em dentes endodonticamente comprometidos.

Em artigo recente, Cordeiro et al. semearam células-tronco da polpa de dentes decíduos de uma linhagem estabelecida em matrizes poliméricas criadas no interior do conduto pulpar de fatias de terceiros molares extraídos. O conjunto fatia de dente e células semeadas no scaffold foi implantado no dorso de camundongos imunodeprimidos. Após determinado tempo foi observada a formação de um tecido que apresentava arquitetura e celularidade com características semelhantes as do tecido pulpar humano. Baseados em análise imunoistoquímica para sialoproteína dentinária e análise 
ultraestrutural com microscopia eletrônica de transmissão, os autores sugeriram que as células-tronco utilizadas se diferenciaram in vivo em células tipo-odontoblásticas.

Considerando que na fase da dentição mista a prevalência de traumas é alta e que o ápice de um dente avulsionado apresenta abertura foramidal favorável à revascularização, se pode especular que com os avanços científicos referentes à biologia molecular e celular, bem como na área da engenharia tecidual, talvez em um futuro não muito distante, a polpa de dentes decíduos em processo de esfoliação seja utilizada como potencial doadora de células-tronco para o tratamento do órgão pulpar de dentes permanentes jovens. Teríamos uma realidade clínica onde células associadas a matrizes biodegradáveis, fatores de crescimento e sinalizadores celulares seriam inseridos no interior do conduto endodôntico, para 0 restabelecimento da vitalidade, da função e da estética.

\section{Periodonto}

O periodonto é uma estrutura complexa que compreende tecido ósseo, cemento, gengiva e ligamento periodontal. Quando acometido por periodontite, o periodonto sofre perda de suporte ósseo que após tratamento apresenta uma limitada capacidade de regeneração. Tradicionalmente, a terapia periodontal regenerativa compreende procedimentos especialmente planejados para restaurar partes dos tecidos de sustentação dos dentes que tenham sido perdidos em decorrência da periodontite (KARRING, LINDHE e CORTELLINI, 2005). A regeneração periodontal envolve a biomodificação da superfície radicular, remoção do biofilme dental, associada à colocação de enxertos ou ao uso de membranas orgânicas. Esses procedimentos visam recrutar células progenitoras para a área com o objetivo de subseqüente diferenciação em células do ligamento periodontal, cementoblastos e osteoblastos. Entretanto, muitos casos considerados bem sucedidos do ponto de vista clínico, mostram que não houve a deposição de um novo cemento do ponto de vista microscópico, mas sim de um epitélio juncional longo (LISTGATEN e ROSEMBERG, 1979). Esta situação de sucesso clínico atinge o objetivo de reparo, porém a situação almejada que é a completa regeneração dos tecidos periodontais (formação de novo cemento, osso alveolar e ligamento periodontal) ainda não foi alcançada. Em estudos experimentais com animais, a cicatrização do ligamento periodontal envolve um aumento do número de células progenitoras na região perivascular que migram para as áreas de osso alveolar e cemento. No entanto não está claro como as alterações inflamatórias no periodonto podem influenciar a distribuição das células-tronco nesses tecidos (GOULD, MELCHER e BRUNETTE, 1980)

As células do ligamento periodontal são uma população celular heterogênea que inclui fibroblastos, células-tronco mesenquimais e células-tronco progenitoras de osteoblastos e cementoblastos. As células do ligamento periodontal humano podem ser distinguidas das células-tronco mesenquimais de medula óssea humana e fibroblastos gengivais pelos genes de apolipoproteina $D$, complexo-DR-a maior de histocompatibilidade e complexo-DR-b maior de histocompatibilidade (FUJITA et al., 2007). A utilização de anticorpos contra antígenos de superfície celular, conhecidos por se expressarem em diferentes populações de células-tronco mesenquimais (STRO-1, CD146 e CD44) podem também localizar células, no ligamento periodontal saudável e afetado por periodontite, consideradas potencialmente como células-tronco adultas. $\mathrm{O}$ entendimento do recrutamento dessas células com capacidade de se desenvolverem em células formadoras de ligamento periodontal ou formadoras de cementoblastos que promoverão uma conexão segura entre cemento e osso alveolar adjacente poderá ajudar a alcançar uma regeneração dos tecidos periodontais no futuro (CHEN et al., 2006).
Atualmente as técnicas utilizadas para promover regeneração periodontal são limitadas para alcançar uma regeneração de todos os tecidos envolvidos. Uma perspectiva biológica para que a regeneração periodontal ocorra, envolve a avaliação do tipo celular apropriado associada a um meio que favoreça a migração, adesão, proliferação e diferenciação celular de forma precisamente coordenada tanto no tempo como no espaço. As estratégias de engenharia tecidual para a regeneração periodontal devem explorar a capacidade regenerativa das células-tronco residentes no periodonto e o seu crescimento em uma estrutura tridimensional, com a subseqüente implantação. O sucesso na superação deste desafio solucionará muitas das limitações encontradas nos métodos regenerativos atuais.

\section{Referências}

ANDERSON, D.J.; GAGE, F.H.; WEISSMAN, I.L. Can stem cells cross lineage boundaries? Nat Med., New York, v. 7, no. 4, p. 393395, Apr. 2001.

BJORNSON, C.R. et al. Turning brain into blood: a hematopoietic fate adopted by adult neural stem cells in vivo. Science, New York, v. 283, no. 5401, p. 534-537, Jan. 1999.

BLAU, H.M.; BRAZELTON, T.R.; WEIMANN, J.M. The evolving concept of a stem cell: entity or function? Cell, Cambridge, v. 105, no. 7, p. 829-841, Jun. 292001.

CHEN, S.C. et al. Location of putative stem cells in human periodontal ligament. J Periodontal Res, Copenhagen, v. 41, no. 6, p. 547-553, Dec. 2006.

CORDEIRO, M.M. et al. Dental pulp tissue engineering with stem cells from exfoliated deciduous teeth. J Endod, Chicago, v. 34, no. 8, p.962-969, Aug. 2008.

FREED, L.E. et al. Biodegradable polymer scaffolds for tissue engineering. Biotechnology (NY), New York, v. 12, no. 7, p. 689-693, Jul. 1994

FUCHS, E.; SEGRE, J.A. Stem cells: a new lease on life. Cell, Cambridge, v. 100, no. 1, p. 143-155, Jan. 72000.

FUJITA, T. et al. Identification of marker genes distinguishing human periodontal ligament cells from human mesenchymal stem cells and human gingival fibroblasts. J Periodontal Res., Copenhagen, v. 42, no. 3, p. 283-286, Jun. 2007.

GARCIA, J.M.Q. et al. Immunolocalization of bone extracellular matrix proteins (type I collagen, osteonectin and bone sialoprotein) in human dental pulp and cultured pulp cells. Int Endod J, Oxford, v.36, no. 6, p. 404-410, Jun. 2003.

GILBERT, S.F. Developmental Biology: 6th ed., Sunderland: Sinauer Associates Inc, 2000. p. 314-318.

GOLDBERG, M. et al. Bioactive molecules and the future of pulp therapy. Am J Dent, San Antonio, v. 16, no. 1, p .66-76, Feb. 2003.

GOULD, T.R.; MELCHER, A.H.; BRUNETTE, D.M. Migration and division of progenitor cell populations in periodontal ligament after 
wounding. J Periodontal Res., Copenhagen, v. 15, no. 1, p. 20-42, Jan. 1980.

GRONTHOS, S. et al. Postnatal human dental pulp stem cells (DPSCs) in vitro and in vivo. Proc Natl Acad Sci U S A, Washington, v. 97 , no. 25 , p. $13625-13630$, Dec. 2000.

GRONTHOS, S. et al. Stem cell properties of human dental pulp stem pulp stem cells. J Dent Res, Chicago, v. 81, no. 8, p. 531-535, Aug. 2002.

HARADA, $H$. et al. Localization of putative stem cells in dental epithelium and their association with notch and FGF signaling. J Cell Biol, New York, v. 147, no. 1, p. 105-120, Oct. 41999.

HOHLFELD, J. et al. Tissue engineered fetal skin constructs for paediatric burns. Lancet, Londres, v. 366 , no. 9488 , p. 840-842, Sep. 3-9. 2005.

JADLOWIEC, J.A.; CELIL, A.B.; HOLLINGER, J.O. Bone tissue engineering:recent advances and promising therapeutic agents. Expert Opin Biol Ther, Londres, v. 3, no. 3, p. 409-423, Jun. 2003.

KARRING, T.; LINDHE, J.; CORTELLINI, P. Terapia Periodontal Regenerativa. In: LINDHE, J.; KARRING, T.; LANG, N. Tratado de Periodontia Clínica e Implantologia Oral. 4. ed. Rio de Janeiro: Guanabara Koogan, 2005. p. 1013.

LANGER, R.; VACANTI, J.P. Tissue engineering. Science, New York, v. 260, no. 5110, p. 920-926, May 141993.

LEITE SEGUNDO, A.V.; VASCONCELOS, B.C.E. Células-tronco e engenharia tecidual: perspectivas de aplicação em Odontologia. Rev Ciênc Méd, Campinas, v. 16, no. 1, p. 23-30, Jan./Fev. 2007.

LISTGARTEN, M.A.; ROSEMBERG, M.M. Histological study of repair following new attachment procedures in human periodontal lesions. $\mathbf{J}$ Periodontol, Chicago, v. 50, no. 7, p. 333-344, 1979.

MARTIN, I, et al. In vitro differentiation of chick embryo bone marrow stromal cells into cartilaginous and bone-like tissues. J Orthop Res, Nova York, v. 16, no. 2, p. 181-189, Mar. 1998.

MIURA, M. et al. SHED: stem cells from human exfoliated deciduous teeth. Proc Natl Acad Sci U S A, Washington, v. 100, no. 10, p. 5807-5812, May 2003.

NAKASHIMA, M.; AKAMINE, A. The application of tissue engineering to regeneration of pulp and dentin in endodontics. J Endod, Baltimore, v.31, no.10, p.711-718, Oct. 2005.

NAKASHIMA, M.; REDDI, A.H. The application of bone morphogenetic proteins to dental tissue engineering. Nat Biotechnol, New York, v. 21, no. 9, p. 1025-1032, Sep.2003.

RAMOSHEBI, L.N. et al. Tissue engineering: TGF-beta superfamily members and delivery systems in bone regeneration. Expert Rev Mol Med, Cambridge, v. 4, no. 20, p.1-11, Sep. 2002.

SACHLOS, E.; CZERNUSZKA, J.T. Making tissue engineering scaffolds work. Review: the application of solid freeform fabrication technology to the production of tissue engineering scaffolds. Eur Cell Mater, Glasgow, v. 5, p. 29-39; discussion 39-40, Jun 30. 2003.
SMITH, A. Reparative processes in dentine and pulp. In: ADDY, M. et al. Tooth Wear and sensivity Clinical Advances in Restorative Dentistry. London: Martin Dunitz, 2000, p.53-66.

SHI, S.; GRONTHOS, S. Perivascular niche of postnatal mesenchymal stem cells in human bone marrow and dental pulp. $\mathbf{J}$ Bone Min Res, Washington, v. 18, no. 4, p. 696-704, Apr. 2003.

STEVENS, M.M. et. al. In vivo engineering of organs: the bone bioreactor. Proc Natl Acad Sci U S A, Washington, v. 102, no. 32, p. 11450-11455, Aug. 92005.

TAYLOR, M.S. et al. Six bioabsorbable polymers: in vitro acute toxicity of accumulated degradation products. J Appl Biomater, New York, v. 5, no. 2, p. 151-157, Summer 1994.

THESLEFF, I.; TUMMERS, M. Stem cells and tissue engineering: prospects for regenerating tissues in dental practice. Med Princ Pract, v. 12, Suppl. 1, p. 43-50, 2003.

TZIAFAS, D. The future role of a molecular approach to pulp-dentinal regeneration. Caries Res, Basel, v. 38, no. 3, p. 314-320, May-Jun. 2004.

YOUNG, C.S. et al. Tissue engineering of complex tooth structures on biodegradable polymer scaffolds. J Dent Res, Chicago, v. 81, no. 10, p. 695-700, Oct. 2002.

VASITA, R.; KATTI, D.S. Growth factor-delivery systems for tissue engineering: a materials perspective. Expert Rev Med Devices, Londres, v. 3, no. 1, p. 29-47 Jan. 2006.

WINGARD, J.; DEMETRI, G. Clinical applications of cytokines and growth factors. Springer Verlag, 1999. 424 p. 